\title{
Role of helicobacter pylori infection in autoimmune diseases
}

\author{
Sarfaraz Ahmed Hasni \\ National Institutes of Health, Bethesda, Maryland, USA
}

\begin{abstract}
Purpose of review-The etiology of most autoimmune diseases remains elusive. Prevailing evidence suggests an environmental trigger in a genetically susceptible individual. Helicobacter pylori (H. pylori) have managed to survive in a hostile environment in its host for long period and have evaded eradication by immune system. Its chronic interaction with the immune system and the ubiquitous presence worldwide makes $H$. pylori an ideal candidate to study as a trigger of autoimmune phenomena. In this review, we would present data regarding the interplay between $H$. pylori and various components of the immune system and its association with various autoimmune diseases.
\end{abstract}

Recent findings-Strong associations of $H$. pylori with some autoimmune diseases such as immune thrombocytopenia have been found; but most other autoimmune disease studies have revealed conflicting data. The chronic survival of $H$. pylori in humans is possible because of an overall downregulation of the body's immune response. In addition to this overall effect on the immune system, there are clinical and epidemiological data suggestive of $H$. pylori infection having a protective role in some autoimmune diseases.

Summary-Based on our review H. pylori status should be checked and treated only in certain autoimmune diseases such as ITP. For majority of the autoimmune diseases role of $H$. pylori remains controversial signifying need for further research.

\section{Keywords}

autoimmune diseases; etiology; H. pylori; infection

\section{INTRODUCTION}

Autoimmune diseases vary significantly in their clinical presentations, but share same pathophysiological mechanism resulting from a loss of self-tolerance. Despite significant advances in our understanding and management of autoimmune diseases, factors leading to this loss of self-tolerance are still poorly understood.

Studies in twins with autoimmune diseases show a much higher concordance rate in identical twins compared with nonidentical twins, indicative of a clear genetic component. However, the concordance rate is not $100 \%$ and the majority of identical twins with autoimmune diseases have a nonaffected twin [1]. In a recent review monozygotic twin concordance rate was reported to be as low as 4.2 for systemic sclerosis [2]. This suggests a

(C) 2012 Wolters Kluwer Health | Lippincott Williams \& Wilkins

Correspondence to Sarfaraz Ahmed Hasni, National Institutes of Health, 9000 Rockville Pike, Bldg. 10, Room 5-5521, Bethesda, MD 20892, USA. Tel: +1 301451 1599; fax: +1 301435 5000; hasnisa@mail.nih.gov.

Conflicts of interest

This study was supported by the Intramural Research Programs of the National Institute of Arthritis and Musculoskeletal and Skin Diseases, National Institutes of Health. 
second environmental factor triggering immune dysregulation in these genetically susceptible hosts leading to autoimmune diseases. Among the various possible environmental triggers, studies looking at the role of various infectious agents have been most promising $\left[3^{\mathbf{Z}}\right]$. Microbial organisms are considered to be likely triggers of autoimmunity because of their ubiquitous presence in the environment and their interaction with the immune system. There are several proposed mechanisms by which microbial organisms can lead to loss of self-tolerance; such asmolecular-mimicry, when shared amino acid sequences between microbial antigens and host proteins leads to a more generalized triggering of immune response against both the host proteins and microbial antigens [4]. Other proposed mechanisms leading to triggering of autoimmunity include polyclonal activation, epitope spread, bystander activation and superantigens [5]. Of the various bacteria and viruses proposed as agents triggering autoimmunity, Helicobacter pylori $(H$. pylori) is one of the most widely studied. This is because of attributes unique to $H$. pylori such as prolonged survival in host environment, worldwide prevalence, and its complex interactions with the host immune system. In this review, we will look at the interactions between $H$. pylori and the immune system in general and the role of $H$. pylori in individual autoimmune diseases.

\section{INTERPLAY OF HELICOBACTER PYLORI AND THE IMMUNE SYSTEM}

H. pylori is a curved gram-negative bacillus first identified from gastric mucosa by Marshall and Warren [6]. Most commonly H. pylori colonize the gastric mucosa in early childhood and can persist throughout life, if no antibiotic therapy is given [7]. Its worldwide prevalence is variable, with highest prevalence in areas with overcrowding and poor sanitation [8]. Presence of $H$. pylori in gastric mucosa has been associated with various gastrointestinal ailments, including peptic ulcers, noncardia gastric adenocarcinoma and gastric mucosa associated lymphoid tissue (MALT) lymphoma [7].

Phylogeographic studies support the presence of helicobacter in our early east African ancestors more than 58000 years ago [9]. H. pylori have managed to persist in its only confirmed hosts (humans) since then, living in the normally inhospitable acidic environment of the stomach. H. pylori have acquired several unique attributes helping it escape clearance through the normal immune mechanisms. This prolonged coexistence of $H$. pylori in humans raises the possibility of a rather symbiotic relationship; in which its persistence may at least in part be beneficial to humans. Inverse association between the presence of $H$. pylori and gastroesophageal reflux disease, asthma and allergic disorders have been reported [7]. Epidemiological data suggest an increase in asthma and autoimmune diseases in populations wherein $H$. pylori infection is aggressively treated and being eradicated.

\section{HELICOBACTER PYLORI AND THE INNATE IMMUNE SYSTEM}

The innate immune system provides the first line of defense against invading microorganisms. This defense mechanism is based on recognition of microbial pathogenassociated molecular patterns (PAMP) through various pattern recognition receptors (PRR) present on the cells of the innate immune system. H. pylori recognition by PRR such as tolllike receptors (TLR) leads to a net anti-inflammatory effect. For example, as compared to lipopolysaccharide (LPS) from Escherichia coli, H. pylori LPS is found to be significantly less potent in promoting a proinflammatory response mediated via TLR 4 signaling [10]. Similarly, $H$. pylori flagellin evades recognition by TLR 5 [11].

\section{HELICOBACTER PYLORI AND THE ACQUIRED IMMUNE SYSTEM}

H. pylori evades activation of acquired immune system through its bacterial antigens. $H$. pylori vacuolatingcytotoxin (VacA) blocks proliferation of $\mathrm{CD}^{+}$helper T-lymphocytes, 
primarily by interfering with the T-cell receptor/interleukin (IL) 2 signaling pathway [12]. In experiments, when bone marrow derived dendritic cells were exposed to $H$. pylori, they failed to produce pro-inflammatory cytokines. In addition, $H$. pylori leads to a preferential priming of naïve T-cells into the anti-inflammatory regulatory T-cell (T-regs) [13"].

High antibody titers against $H$. pylori are usually present in infected individuals. But unlike other antimicrobial antibodies, anti-H. pylori antibodies (especially immunoglobulin (Ig)A antibodies) promote the presence of bacteria [14]. Studies in mouse models showed that Blymphocyte activation by helicobacter species leads to an increase in the number of IL-10 (an anti-inflammatory cytokine) producing T-regs [15'].

\section{HELICOBACTER PYLORI AND THE AUTOIMMUNE DISEASES-INDUCER OR PROTECTOR?}

Evidence presented above indicates an overall downregulation of the host immune response in $H$. pylori infected individuals. However, the persistent presence of $H$. pylori in gastric mucosa results in chronic immune system activation with ongoing cytokine signaling, infiltration of gastric mucosa by neutrophils, macrophages, lymphocytes, as well as production of antibodies and effector T-cells [16].

There are several proposed mechanisms by which $H$. pylori may cause loss of self-tolerance. These include molecular mimicry, polyclonal activation, epitope spread, by stander activation and super antigen phenomena. One example of molecular mimicry with the $H$. pylori antigens leading to an autoimmune disease is in the case of autoimmune chronic gastritis (AIG) in which, the recognized autoantigen is $\mathrm{H}^{+}, \mathrm{K}^{+}$-adenosine triphosphatase $\left(\mathrm{H}^{+}, \mathrm{K}^{+}\right.$-ATPase). The activated $\mathrm{CD} 4^{+} \mathrm{T}$-lymphocytes in AIG were shown to cross react with $\mathrm{H}^{+}, \mathrm{K}^{+}$-ATPase and $\mathrm{H}$. pyloriantigens [17]. Similarly in studies on mice, B lymphocytes stimulated by $H$. pylor's urease antigen revealed production of several autoantibodies such as: IgM-type rheumatoid factor (RF IgM), antisingle-stranded DNA antibody, and antiphosphatidylcholine (anti-PC) antibody [18"].

Conversely, there is some recent data suggestive of a protective effect of $H$. pylori against auto-immune and allergic diseases. A recent meta-analysis suggested a protective role of $H$. pylori in inflammatory bowel disease [19]. An inverse relationship between $H$. pylori infection and allergic conditions is also reported. Rate of asthma was found to be lower in children who were $H$. pylori positive when compared with those who were $H$. pylori negative [ $\left.20^{\bullet}\right]$. In a Japanese cohort an inverse association of $H$. pylori seropositivity and multiple sclerosis (MS) was reported [21]. Based on a review of literature recently, we concluded that in most auto-immune diseases the role of $H$. pylori remains inconclusive [22"'].

\section{Helicobacter pylori and immune thrombocytopenic purpura}

Immune thrombocytopenic purpura (ITP) is an autoimmune disease resulting from antibodies against platelet glycoproteins. Several microbial agents causing chronic infections such as HIV, Hepatitis $\mathrm{C}$ virus and $\mathrm{H}$. pylori have been shown to be associated with ITP.

In their recent review, Stasi et al. [23] reported worldwide prevalence of $H$. pylori in ITP patients from 25 studies. The result from these studies revealed an overall prevalence of $62.3 \%$. However, when matched with age and geographic area prevalence rate of $H$. pylori infection in most of these studies were similar to the healthy population. 
Several studies have attempted to explain the underlying pathogenic mechanism of $H$. pylori induced ITP. Most prevailing hypothesis suggest molecular mimicry between one of the $H$. pylori antigens and platelet glycoproteins causing production of cross-reacting autoantibodies [24]. A detailed discussion of $H$. pylori induced pathogenesis of ITP is beyond the scope of this review.

Eradication of $H$. pylori in patients with ITP leads to sustained increase in their platelet counts. A little over $50 \%$ of patients are expected to show an improvement in their platelet counts after eradication of $H$. pylori [25]. This response rate correlates with the prevalence of $H$. pylori in the population being treated, with higher response rates reported from Japan and much lower rates in studies from United States.

Even though there is evidence of $H$. pylori infection in the development of ITP, its exact pathogenetic role is largely unknown.

\section{Helicobacter pylori and rheumatoid arthritis}

Looking for a microorganism causing rheumatoid arthritis (RA) dates back to the 19th century [26]. In a cohort of 187 samples from RA patients, $80.4 \%$ were found to be seropositive for $H$. pylori; however this was not significantly different from the control population, reflective of an overall increased prevalence [27]. A study of 1815 Japanese RA patients, $49.3 \%$ were reported to have $H$. pylori antibodies, which was lower compared with the healthy Japanese individuals [28]. However, another study from Japan looking at the prevalence of $H$. pylori infection in RA patients reported a much higher percentage (61.4\%) [29]. Prevalence of $H$. pylori in the study of a European population with RA was reported to be $48 \%$, which is similar to healthy individuals in the Western countries [30]. However, in the same study RA patients with $H$. pylori seropositivity showed a trend towards more severe disease and its eradication led to a significant improvement in RA related clinical outcomes [30]. Hence, the role of $H$. pylori infection in causing RA is not clear; but its presence in patients with RA might result in a more severe phenotype.

\section{Helicobacter pylori and systemic lupus erythematosus}

A recent review looked at the role of various infectious agents including $H$. pylori in the development of SLE; concluding an overall negative association with H. pylori [31]. Studies done on mice revealed that $H$. pylori urease exposure can lead to production of antiss-DNA antibodies [32]. In a study of 466 patients with SLE matched with 466 controls, SLE patients were less frequently seropositive (36.5\%) for $H$. pylori as compared to healthy controls (42.9\%) $P=0.045$ [33]. This negative association was even stronger for AfricanAmerican female SLE patients as compared to controls (38.1 versus $60.2 \% ; P=0.0009$ ).

In another study patients with SLE were found to have lower titers of anti-H. $p$ ylori antibodies when compared to patients with other autoimmune diseases [34]. These studies had several limitations but all of them are indicative of a negative association between SLE and $H$. pylori infection. This raises an interesting question: could $H$. pylori infected individuals be protected against development of SLE?

\section{Helicobacter pylori and sjögren's syndrome}

Some earlier studies suggested a possible association between H. pylori and Sjögren's syndrome [34]. One of the studies suggested a possible link between antibodies produced against heat shock protein (HSP 60) of H. pylori and development of Sjögren's syndrome [35]. 
However subsequent studies failed to show any association between $H$. pylori seropositivity and presence of Sjögren's syndrome. In a study of 164 Swedish patients with Sjögren's syndrome, $H$. pylori seroprevelance (45\%) was similar to the controls [36]. In addition there was no association found between $H$. pylori status and abnormal levels of autoantibodies or abnormal lip biopsy in these patients. In a separate cohort of 54 patients with Sjögren's syndrome, seroprevelance of $H$. pylori was $57 \%$ as opposed to $62 \%$ in the controls [37]. Authors also concluded that eradication of $H$. pylori was not associated with improvement of dyspeptic symptoms in patients with Sjögren's syndrome.

\section{Helicobacter pylori and polymyositis and dermatomyositis}

Limited data is available on any role of $H$. pylori and polymyositis (PM)/dermatomyositis (DM). Review of the available literature revealed no significant difference in frequency of $H$. pylori in patients with PM/DM compared with the controls $[35,38]$.

\section{Helicobacter pylori and systemic sclerosis}

Several environmental factors including microbial organisms have long been debated as possible triggers for systemic sclerosis.

In a study of 12 European scleroderma patients, five (42\%) were found to be positive for $H$. pylori infection [39]. In a much larger cohort of 124 Japanese patents with systemic sclerosis, seroprevelance of $H$. pylori was reported at $55.6 \%$, much higher than the healthy controls [40]. Yet another study found no difference in $H$. pylori infection rates between patients with systemic sclerosis and the controls [41]. However, most of these patients in the study were infected with a more virulent (CagA) strain of $H$. pylori as compared to infected controls.

Several studies looked at association between specific manifestations of scleroderma and presence of $H$. pylori infection. In a Japanese study 64 patients with scleroderma underwent endoscopy to assess reflux esophagitis. Being infected with $H$. pylori was shown to be protective against development of reflux esophagitis in patients with scleroderma [42]. There are conflicting reports of association between $H$. pylori and Raynaud's phenomena as reported in a recent review [43"].

\section{Helicobacter pylori and vasculitis}

In their search for a microbial agent causing Behcet's disease several investigators have looked at the seroprevelance of $H$. pylori in Behcet's disease patients. Variable rates of $H$. pylori positivity are reported in patients with Behcet's disease from $85 \%$ (higher than controls) to $73.3 \%$ (lower than controls) $[44,45]$.

Several published case reports suggested an association of $H$. pylori infection with HenochSchönlein purpura; with resolution of symptoms coinciding with the eradication of $H$. pylori infection [46].

In a study looking at serological evidence of various infectious agents in patients with Granulomatosis with polyangitis (Wegner's Granulomatosis), H. pylori IgG antibodies were reported to be more common in patients as compared to controls [47].

Hence, there is some evidence of an association of $H$. pylori infection with various vasuilitides but further research is needed to infer any causality. 


\section{Helicobacter pylori and fibromyalgia}

Etiology and pathogenesis of fibromyalgia (FMG) remains controversial. Studies focusing on association of several viral and bacterial microorganisms and FMG have been published, but literature regarding role of $H$. pylori is rather limited. A recent study explored association of FMG with $H$. pylori seropositivity in 65 patients and compared it with 41-year old and gender-matched controls [48 $]$. Prevalence of $\operatorname{IgG}$ anti- $H$. pylori antibodies was significantly higher in FMG patients (30.8\%) as compared to controls (17.1\%). However, among these patients, there was no difference in clinical manifestations of FMG between $H$. pylori seropositive versus seronegative individuals. Another study of 28 female FMG patients reported similar rates of $H$. pylori seropositivity in patients and controls [49].

\section{CONCLUSION}

H. pylori infection is very common and widespread. It has survived in its host (humans) for at least last 58000 years. $H$. pylori have extensive interactions with immune system resulting in its downregulation. Its role as a causative agent of autoimmune diseases in genetically susceptible host has been extensively studied. Studies looking at the presence of H. pylori in various autoimmune diseases found mixed results with some even suggesting a protective role. However, mechanistic studies establishing causality are lacking. Further research looking at the possible role of $H$. pylori in autoimmune diseases is needed.

\section{Acknowledgments}

Author would like to thank Dr Gabor Illei for his guidance and review of the article.

\section{REFERENCES AND RECOMMENDED READING}

Papers of particular interest, published within the annual period of review, have been highlighted as:

- of special interest

- of outstanding interest

Additional references related to this topic can also be found in the Current World Literature section in this issue (pp. 000-000).

1. Salvetti M, Ristori G, Bomprezzi R, et al. Twins: mirrors of the immune system. Immunol Today. 2000; 21:342-347. [PubMed: 10871876]

2. Bogdanos DP, Smyk DS, Rigopoulou EI, et al. Twin studies in autoimmune disease: genetics, gender and environment. J Autoimmun. 2011

3-. Chervonsky AV. Influence of microbial environment on autoimmunity. Nat Immunol. 2012; 11:28-35. This article explores the interaction between infectious agents and autoimmunity. [PubMed: 20016507]

4. Cooke A, Ferraccioli GF, Herrmann M, et al. Induction and protection of autoimmune rheumatic diseases. The role of infections Clin Exp Rheumatol. 2008; 26 (1 Suppl 48):S1-7.

5. Amital H, Govoni M, Maya R, et al. Role of infectious agents in systemic rheumatic diseases. Clin Exp Rheumatol. 2008; 26 (1 Suppl 48):S27-S32. [PubMed: 18570751]

6. Marshall BJ, Warren JR. Unidentified curved bacilli in the stomach of patients with gastritis and peptic ulceration. Lancet. 1984; 1:1311-1315. [PubMed: 6145023]

7. Cover TL, Blaser MJ. Helicobacter pylori in health and disease. Gastroenterology. 2009; 136:18631873. [PubMed: 19457415]

8. Goh KL, Chan WK, Shiota S, Yamaoka Y. Epidemiology of Helicobacter pylori infection and public health implications. Helicobacter. 2011; 16 (Suppl 1):1-9. [PubMed: 21896079] 
9. Linz B, Balloux F, Moodley Y, et al. An African origin for the intimate association between humans and Helicobacter pylori. Nature. 2007; 445:915-918. [PubMed: 17287725]

10. Perez-Perez GI, Shepherd VL, Morrow JD, Blaser MJ. Activation of human THP-1 cells and rat bone marrow-derived macrophages by Helicobacter pylori lipopolysaccharide. Infect Immun. 1995; 63:1183-1187. [PubMed: 7890370]

11. Gewirtz AT, Yu Y, Krishna US, et al. Helicobacter pylori flagellin evades toll-like receptor 5mediated innate immunity. J Infect Dis. 2004; 189:1914-1920. [PubMed: 15122529]

12. Gebert B, Fischer W, Weiss E, et al. Helicobacter pylori vacuolating cytotoxin inhibits T lymphocyte activation. Science. 2003; 301:1099-1102. [PubMed: 12934009]

13-. Muller A, Oertli M, Arnold IC. H. pylori exploits and manipulates innate and adaptive immune cell signaling pathways to establish persistent infection. Cell Commun Signal. 2011; 9:25. Authors explain various interactions of $H$. pylori with immune system leading to chronic infection. [PubMed: 22044597]

14. Akhiani AA, Schon K, Franzen LE, et al. Helicobacter pylori-specific antibodies impair the development of gastritis, facilitate bacterial colonization, and counteract resistance against infection. J Immunol. 2004; 172:5024-5033. [PubMed: 15067084]

15". Sayi A, Kohler E, Toller IM, et al. TLR-2-activated B cells suppress Helicobacter-induced preneoplastic gastric immunopathology by inducing T regulatory-1 cells. J Immunol. 2011; 186:878-890. Describes the role of the innate immune system in perpetuating $H$. pylori survival in gastric mucosa. [PubMed: 21149607]

16. Blaser MJ, Atherton JC. Helicobacter pylori persistence: biology and disease. J Clin Invest. 2004; 113:321-333. [PubMed: 14755326]

17. Amedei A, Bergman MP, Appelmelk BJ, et al. Molecular mimicry between Helicobacter pylori antigens and $\mathrm{H}^{+}, \mathrm{K}^{+}$-adenosine triphosphatase in human gastric autoimmunity. J Exp Med. 2003; 198:1147-1156. [PubMed: 14568977]

18- Kobayashi F, Watanabe E, Nakagawa Y, et al. Production of autoantibodies by murine B-1a cells stimulated with Helicobacter pylori urease through toll-like receptor 2 signaling. Infect Immun. 2011; 79:4791-4801. Mouse model explaining H. pylori leading to development of autoimmunity through interactions with the innate immune system. [PubMed: 21947775]

19. Luther J, Dave M, Higgins PD, Kao JY. Association between Helicobacter pylori infection and inflammatory bowel disease: a meta-analysis and systematic review of the literature. Inflamm Bowel Dis. 2010; 16:1077-1084. [PubMed: 19760778]

20m. Zevit N, Balicer RD, Cohen HA, et al. Inverse association between Helicobacter pylori and pediatric asthma in a high-prevalence population. Helicobacter. 2012;17:30-35. This is an epidemiological study showing lower incidence of asthma in $H$. pylori positive patients. [PubMed: 22221613]

21. Li W, Minohara M, Su JJ, et al. Helicobacter pylori infection is a potential protective factor against conventional multiple sclerosis in the Japanese population. J Neuroimmunol. 2007; 184:227-231. [PubMed: 17296235]

22m. Hasni S, Ippolito A, Illei GG. Helicobacter pylori and autoimmune diseases. Oral Dis. 2011; 17:621-627. This is a recent review of $H$. pylori involvement in autoimmune diseases with focus on its pathogenesis and interactions with the immune system. [PubMed: 21902767]

23. Stasi R, Willis F, Shannon MS, Gordon-Smith EC. Infectious causes of chronic immune thrombocytopenia. Hematol Oncol Clin North Am. 2009; 23:1275-1297. [PubMed: 19932434]

24. Franchini M, Plebani M, Montagnana M, et al. Pathogenesis, laboratory, and clinical characteristics of Helicobacter pylori-associated immune thrombocytopenic purpura. Adv Clin Chem. 2010; 52:131-144. [PubMed: 21275342]

25. Arnold DM, Bernotas A, Nazi I, et al. Platelet count response to H. pylori treatment in patients with immune thrombocytopenic purpura with and without $H$. pylori infection: a systematic review. Haematologica. 2009; 94:850-856. [PubMed: 19483158]

26. Benedek TG. The history of bacteriologic concepts of rheumatic fever and rheumatoid arthritis. Semin Arthritis Rheum. 2006; 36:109-123. [PubMed: 16884972]

27. Meron MK, Amital H, Shepshelovich D, et al. Infectious aspects and the etiopathogenesis of rheumatoid arthritis. Clin Rev Allergy Immunol. 2010; 38:287-291. [PubMed: 19575154] 
28. Tanaka E, Singh G, Saito A, et al. Prevalence of Helicobacter pylori infection and risk of upper gastrointestinal ulcer in patients with rheumatoid arthritis in Japan. Mod Rheumatol. 2005; 15:340-345. [PubMed: 17029090]

29. Ishikawa N, Fuchigami T, Matsumoto T, et al. Helicobacter pylori infection in rheumatoid arthritis: effect of drugs on prevalence and correlation with gastroduodenal lesions. Rheumatology (Oxford). 2002; 41:72-77. [PubMed: 11792883]

30. Zentilin P, Seriolo B, Dulbecco P, et al. Eradication of Helicobacter pylori may reduce disease severity in rheumatoid arthritis. Aliment Pharmacol Ther. 2002; 16:1291-1299. [PubMed: 12144579]

31. Francis L, Perl A. Infection in systemic lupus erythematosus: friend or foe? Int J Clin Rheumtol. 2010; 5:59-74. [PubMed: 20209114]

32. Yamanishi S, Iizumi T, Watanabe E, et al. Implications for induction of autoimmunity via activation of B-1 cells by Helicobacter pylori urease. Infect Immun. 2006; 74:248-256. [PubMed: 16368978]

33. Sawalha AH, Schmid WR, Binder SR, et al. Association between systemic lupus erythematosus and Helicobacter pylori seronegativity. J Rheumatol. 2004; 31:1546-1550. [PubMed: 15290733]

34. Showji Y, Nozawa R, Sato K, Suzuki H. Seroprevalence of Helicobacter pylori infection in patients with connective tissue diseases. Microbiol Immunol. 1996; 40:499-503. [PubMed: 8865155]

35. Aragona P, Magazzu G, Macchia G, et al. Presence of antibodies against Helicobacter pylori and its heat-shock protein 60 in the serum of patients with Sjogren's syndrome. J Rheumatol. 1999; 26:1306-1311. [PubMed: 10381048]

36. Theander E, Nilsson I, Manthorpe R, et al. Seroprevalence of Helicobacter pylori in primary Sjogren's syndrome. Clin Exp Rheumatol. 2001; 19:633-638. [PubMed: 11791633]

37. Sorrentino D, Faller G, DeVita S, et al. Helicobacter pylori associated antigastric autoantibodies: role in Sjogren's syndrome gastritis. Helicobacter. 2004; 9:46-53. [PubMed: 15156903]

38. Kalabay L, Fekete B, Czirjak L, et al. Helicobacter pylori infection in connective tissue disorders is associated with high levels of antibodies to mycobacterial hsp65 but not to human hsp60. Helicobacter. 2002; 7:250-256. [PubMed: 12165033]

39. Reinauer S, Goerz G, Ruzicka T, et al. Helicobacter pylori in patients with systemic sclerosis: detection with the 13C-urea breath test and eradication. Acta Derm Venereol. 1994; 74:361-363. [PubMed: 7817672]

40. Yazawa N, Fujimoto M, Kikuchi K, et al. High seroprevalence of Helicobacter pylori infection in patients with systemic sclerosis: association with esophageal involvement. J Rheumatol. 1998; 25:650-653. [PubMed: 9558164]

41. Danese S, Zoli A, Cremonini F, Gasbarrini A. High prevalence of Helicobacter pylori type I virulent strains in patients with systemic sclerosis. J Rheumatol. 2000; 27:1568-1569. [PubMed: 10852299]

42. Yamaguchi K, Iwakiri R, Hara M, et al. Reflux esophagitis and Helicobacter pylori infection in patients with scleroderma. Intern Med. 2008; 47:1555-1559. [PubMed: 18797112]

43-. Radic M, Kaliterna DM, Radic J. Helicobacter pylori infection and systemic sclerosisis there a link? Joint Bone Spine. 2011; 78:337-340. This is a review of H. pylori role in systemic sclerosis. [PubMed: 21145276]

44. Aksoz MKUB, Zeren I, Onder G, Ekinci N, Kosay S. The upper gastrointestinal endoscopic and rectosigmoidoscopic findings in Behcet's disease. Turk J Gastroenterol. 1995; 6:172-174.

45. Ersoy O, Ersoy R, Yayar O, et al. H pylori infection in patients with Behcet's disease. World J Gastroenterol. 2007; 13:2983-2985. [PubMed: 17589951]

46. Mytinger JR, Patterson JW, Thibault ES, et al. Henoch-Schonlein purpura associated with Helicobacter pylori infection in a child. Pediatr Dermatol. 2008; 25:630-632. [PubMed: 19067870]

47. Lidar M, Lipschitz N, Langevitz P, et al. Infectious serologies and autoantibodies in Wegener's granulomatosis and other vasculitides: novel associations disclosed using the Rad BioPlex 2200. Ann NY Acad Sci. 2009; 1173:649-657. [PubMed: 19758211] 
48-. Akkaya N, Akkaya S, Polat Y, et al. Helicobacter pylori seropositivity in fibromyalgia syndrome. Clin Rheumatol. 2011; 30:43-49. This is a study of $H$. pylori serological status in fibromyalgia patients. [PubMed: 21120564]

49. Malt EA, Olafsson S, Ursin H. Fibromyalgia: a manifestation of Helicobacter pylori infection? Scand J Rheumatol. 2004; 33:131-1131. 


\section{KEY POINTS}

- Chronic infection with H. pylori has significant interactions with immune system resulting in its downregulation.

- $\quad$ Role of $H$. pylori in pathogenesis of autoimmune diseases remains controversial with some evidence even suggesting a protective role.

- There is data suggesting positive association of $H$. pylori with immune thrombocytopenic purpura. 